\title{
스마트폰 어플리케이션을 이용한 뇌졸중 환자의 등뼈 만곡, 골반기울기 측정에 대한 타당도 연구
}

\author{
오승준, $\mathrm{PT}, \mathrm{PhD}^{1}$, 김도현, $\mathrm{PT}, \mathrm{PhD}^{* 2}$ \\ 1청담병원 재활치료센터, ${ }^{* 2}$ 위덕대학교 물리치료학과
}

\author{
Validity of Thoracic Kyphosis and Pelvic Tilt Using Smartphone Application in Chronic Stroke Patients \\ Seung-Jun Oh, PT, PhD' ${ }^{1}$, Do-Hyun Kim, PT, $\mathrm{PhD}^{* 2}$ \\ 'Dept. of Physical Therapy, Cheongdam Rehabilitation Hospital, Republic of Korea \\ ${ }^{* 2}$ Dept. of Physical Therapy, Uiduk University, Republic of Korea
}

\begin{abstract}
Purpose The aim of this study was to determine of validity of thoracic kyphosis and pelvic tilt using smartphone application in chronic stroke patients. Methods Subjects were stroke patients $(\mathrm{n}=15)$ and healthy controls $(\mathrm{n}=15)$. The minimal detectable change (MDC) and standard error of measurement (SEM) were estimated to determine a real change for thoracic kyphosis and pelvic tilt angle. Correlation was analyzed to explore the relationships between smartphone application and inclinometer. Results The thoracic kyphosis and pelvic tilt angle had an SEM of 1.88, 1.10, MDC of $3.68,2.17$. The high correlation was observed between the measured with the inclinometer data and the measured by the smartphone application data (thoracic kyphosis, $\mathrm{r}=0.93, \mathrm{p}<0.001$; pelvic tilt $\mathrm{r}=0.93, \mathrm{p}<0.001$ ). Conclusion Our experimental results indicate that smartphone application was appropriate to measure thoracic kyphosis and pelvic tilt angle in stroke patients.
\end{abstract}

Key words Pelvic tilt, Smartphone Application, Stroke, Thoracic kyphosis

Corresponding author Do-Hyun Kim (kimdh@uu.ac.kr)

Received date 08 October 2020

Revised date 12 October 2020

Accept date 14 October 2020

이 성과는 정부(과학기술정보통신부)의 재원으로 한국연구재단의 지원을 받아 수행된 연구임(No. 2019R1G1A1100698).

\section{I. 서 론}

자세조절은 중력에 대항하여 몸통의 안정성과 균형을 유지하 는 능력으로 정의하며, 감각계, 근골격계, 신경계의 상호작용 이 필요하다. 적절한 자세조절은 앉거나 선 자세 유지하기, 이 동하기, 일상생활 동작 수행하기를 위해서 필요한 기본적인 요소 중 하나이다. ${ }^{1}$ 하지만 뇌졸중 환자들은 중추신경계의 손 상으로 감각기능이 낮아질 뿐만 아니라 과도한 근 긴장도, 저 하된 근 긴장도, 불규칙한 근 긴장도와 같은 근 긴장도의 변 화 그리고 근력 약화로 인하여 자세조절에 어려움을 겪는다. ${ }^{2}$ 따라서 뇌졸중 환자들은 앉은 자세에서 몸통을 바로 세우지 못하며, 앉은 자세에서 건강한 성인과 비교하여 과도한 에너 지 소비를 하기 때문에 근 피로를 유발하게 되고, 기능적 수 행능력과 사회적 참여에 제한된다. 또한 부적절한 자세로 인 하여 근골격계 통증을 호소하기도 한다. ${ }^{3)}$ 시상면에서 등뼈 만
곡과 골반 기울기는 뇌졸중환자의 기능을 평가하고, 치료효과 를 비교해보기 위하여 측정된다. 일반적으로, 등뼈는 20-45 사이의 뒤굽이각을 형성하며 상부 척추의 각도가 $45^{\circ}$ 를 넘어 서면 과도한 척주뒤굽음증(hyperkyphosis)으로 분류된다. ${ }^{4)}$ 등뼈 뒤굽음증의 증가는 신체적 기능을 저하시킬 뿐 아니라, 호흡기능에 영향을 미치며 나아가서는 삶의 질에 영향을 미치 기 때문에 적절한 등뼈 뒤굽이를 유지하는 것이 중요하다., ${ }^{5,6}$ 골반은 척추와 하지를 연결하며, 몸통을 바로 세우기 위해서 는 적절한 골반 기울기가 요구된다. 하지만 뇌졸중 환자들은 시상면에서 골반의 전방과 후방 기울기의 비대칭이 발생하기 때문에 몸통 바로 세우기에 제한을 가지게 되며 이는 하지의 안쪽돌림과 바깥쪽돌림에 영향을 미치게 된다. ${ }^{7}$ 이와 같은 이 유에서 뇌졸중 환자들은 건강한 성인과 비교하여 앉고, 서는 능력에 차이를 보인다. 또한 골반의 전방, 후방 기울기는 척추 와 몸통 자세조절에 영향을 미치기 때문에 뇌졸중 환자에서 등뼈의 만곡과 골반 기울기에 대한 적절한 평가 방법이 요구 된다. ${ }^{8)}$ 고전적으로 시상면에서 척추의 정렬을 측정하는 방법 
으로는 방사선 촬영에 의한 방법, 줄자를 이용하는 방법, 인클 리노미터를 이용하는 측정방법이 있다. ${ }^{910)}$ 방사선 촬영에 의 한 방법은 반복적인 방사선 촬영에 의한 방사선 노출에 위험 이 있으며, 정적인 자세에서만 측정이 가능하다. ${ }^{11)}$ 줄자를 이 용한 방법은 척추의 굽힘과 폄을 측정하기에는 적합한 방법이 지만 골반의 기울기를 측정하는 것은 제한이 있다. ${ }^{10)}$ 임상적 인 환경에서는 반복적으로 측정이 가능하고, 신뢰도가 우수하 며, 측정시간이 짧은 방법이 필요하다. 인클리노미터를 이용한 측정방법은 척추 각도와 골반의 기울기를 모두 측정할 수 있 으며 척추 각도 측정에 대한 신뢰도가 우수하다는 장점이 있 다. ${ }^{12)}$ 최근 스마트폰 어플리케이션이 개발됨에 따라 스마트폰 어플리케이션을 이용하여 건강한 성인의 척추 정렬에 대한 연 구가 이루어지고 있다. 하지만 아직까지 뇌졸중 환자를 대상 으로 스마트폰 어플리케이션을 이용한 등뼈 만곡과 골반 기울 기에 대한 연구가 부족하다. 또한 뇌졸중 환자의 등뼈 만곡과 골반 기울기를 건강한 성인과 비교해 본다면 척추와 근육의 균형을 이해하고 회복시키는데 도움이 될 것으로 생각된다. 따라서 본 연구에서는 첫째, 스마트폰 어플리케이션을 이용하 여 뇌졸중 환자의 등뼈 뒤굽이각과 골반기울기를 측정하고, 측정의 신뢰도를 알아보고자 함이며, 둘째, 뇌졸중 환자와 건 강한 성인의 시상면상 등뼈 뒤굽이각과 골반기울기를 비교하 여 시상면의 정렬차이를 알아보고자 함이다.

\section{II. 연구 방법}

\section{1. 연구 대상자}

본 연구의 대상은, 뇌졸중으로 진단받은 15 명의 뇌졸중 환자 와 건강한 성인 15 명을 대상으로 하였으며, 대상자의 선정조 건은 뇌졸중 진단을 받고 6개월 이상 경과한 자, 보조기구 없 이 독립적으로 1 분 이상 서기가 가능한 자, 연구자의 지시사 항을 이해하고 수행 가능한 자, 척추와 하지의 정형외과적 질 환이 없는 자를 대상으로 하였다. 모든 대상자들은 연구에 참 여하기 전 연구절차에 대한 설명을 들었으며, 연구기간 도중 참여하지 못하더라도 불이익이 없음을 인지하고 연구참여에 동의하였다. 표본크기 산출을 위하여 $\mathrm{G}$ power 3.1 .3

Table 1. General characteristics of the subjects

\begin{tabular}{ccc}
\hline & $\begin{array}{c}\text { Stroke patients } \\
(\mathrm{n}=15)\end{array}$ & $\begin{array}{c}\text { Healthy controls } \\
(\mathrm{n}=15)\end{array}$ \\
Age (years) & $62.13 \pm 8.32$ & $64.86 \pm 9.35$ \\
Sex (Males:Females) & $10: 5$ & $10: 5$ \\
Height $(\mathrm{cm})$ & $163.13 \pm 9.81$ & $167.73 \pm 8.21$ \\
Weight $(\mathrm{kg})$ & $61.80 \pm 9.95$ & $61.20 \pm 9.43$ \\
\hline
\end{tabular}

(University of Dusseldorf, Dusseldorf, Germany)을 이용 하였으며, 유의수준은 5\%,80\% 파워, 효과크기 0.85 조건하에 최소 표본크기는 군별 10 명으로 확인되었다. 본 연구에서는 대상자의 중도 탈락을 고려하여 군별 15 명씩, 총 30 명을 모집 하였다. 대상자의 일반적인 특성은 Table 1 과 같다.

\section{2. 측정도구}

안드로이드 스마트폰과 iHandy Level 어플리케이션을 이용 하였다. iHandy Level 어플리케이션은 측정 값을 실시간으로 보여주는 디스플레이와 등뼈의 만곡과 골반의 기울기를 결정 할 수 있는 디지털 인클리노미터로 구성되어 있다. 또한 누구 에게나 쉽게 적용할 수 있으며, 측정 시간이 10 분 이내이기 때문에 쉽고, 간단하게 평가할 수 있다는 장점이 있는 도구이 다. iHandy Level 어플리케이션은 일반적으로 척추 기울기를 측정하기 위해 사용하는 수평계(inclinometer)와 높은 상관관 계를 나타냈으며 $(\mathrm{r}=0.86)$, 검사자간 신뢰도 0.90 , 검사-재검사 신뢰도0.85로 우수한 수준을 보인다.

\section{3. 측정방법}

측정에 앞서 목을 부드럽게 굽히고 펴기를 3회 반복하고, 숨 을 들여 마시고 내쉬기를 3 회 반복하여 대상자가 편안한 위치 를 찾을 수 있도록 하였다. 측정을 위하여 대상자들은 다리를 어깨 넓이로 벌리고 선 자세를 취하였다. 등뼈의 만곡을 측정 하기 위해서, 일곱 번째 목뼈와 첫 번째 등뼈 사이, 열 두번째 등뼈와 첫 번째 허리뼈 사이에 각각 스마트폰의 아랫면을 위 치하여 각도를 측정하고 두 측정값을 더하여 등뼈 만곡으로 결정하였다. ${ }^{13)}$ 첫 번째 등뼈는 일곱 번째 목뼈에서 아래로 내 려가면서 결정하였고, 첫 번째 허리뼈는 다섯 번째 허리뼈에 서 올라가면서 촉지하여 결정하였다. 골반 기울기를 측정하기 위해서 다섯 번째 허리뼈와 첫 번째 엉치뼈 사이에 스마트폰 의 아랫면을 위치하여 골반 기울기를 측정하였다. ${ }^{14)}$ 다섯 번

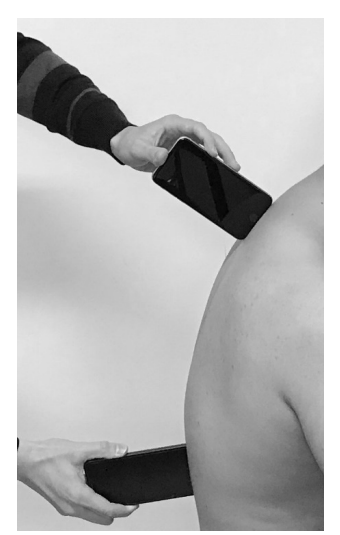

Figure 1. Assessment of thoracic kyphosis 
째 허리뼈를 촉지하기 위해서 네 번째 허리뼈를 장골능(iliac crest)의 높이로 결정한 후 내려가면서 촉지하여 결정하였다. 골반 기울기는 $0^{\circ}$ 는 골반이 수직으로 위치해 있음을 나타내 며, 양의 값이 클수록 골반이 앞쪽으로 기울어져 있는 것을 의미하고, 음의 값은 골반이 뒤쪽으로 기울어진 것을 의미한 다. 측정은 총 3 번 하여 평균값을 분석에 이용하였다. ${ }^{15)}$

\section{4. 통계방법}

통계학적 분석을 위하여 윈도우용 PASW 프로그램 버전 18.0 을 이용하였으며 모든 자료 값은 평균과 표준편차로 나타냈 다. 검사-재검사 신뢰도를 확인하기 위하여 $95 \%$ 신뢰구간의 급내상관계수(Intraclass correlation coefficient)를 이용하 였으며, 뇌졸중 환자분과 건강한 성인의 등뼈 만곡과 골반 기 울기를 비교하기 위하여 독립표본 t검정(Independent t-test) 을 실시하였다. 또한 표준오차(standard error of measurement, SEM)값과 최소감지변화(minimal detectable change, $\mathrm{MDC}$ )값을 계산하였다. 급내상관계수는 값이 0.75 이상이면 신뢰도가 우수한 것으로, 0.75 미만이면 신뢰도가 중등도 수 준인 것으로 결정하였으며, ${ }^{16)}$ 모든 통계학적 유의수준은 0.05 로 하였다.

\section{III. 결 과}

뇌졸중환자의 검사-재검사 신뢰도는 등뼈 만곡 0.93 , 골반 기 울기 0.95로 확인되었으며, 표준오차(standard error of measurement, SEM)는 등뼈 만곡 1.88 , 골반 기울기 1.10 으 로 확인되었다. 임상적으로 의미 있는 최소한의 변화를 나타 내는 최소감지변화(minimal detectable change, MDC)는 등뼈 만곡 3.68 , 골반 기울기 2.17로 확인되었다. 인클리노미 터로 측정한 측정값과 스마트폰 어프리케이션으로 측정한 값
사이에서 높은 상관관계가 관찰되었다(등뼈 만곡, $\mathrm{r}=0.93$, $\mathrm{p}<0.001$; 골반 기울기 $\mathrm{r}=0.93, \mathrm{p}<0.001$ ) (Table 2). 뇌졸중 환자와 건강한 성인의 등뼈 만곡과 골반 기울기를 비교한 결 과 등뼈 만곡은 뇌졸중 환자군에서 $51.39 \pm 7.71^{\circ}$, 건강한성 인에서 $32.49 \pm 2.29^{\circ}$ 로 확인되어 유의한 차이를 보였으며 $(\mathrm{t}=-9.79, \mathrm{p}=0.002)$, 골반 기울기는 뇌졸중 환자군에서 24.08 $\pm 4.96^{\circ}$, 건강한 성인에서 $11.15 \pm 1.68^{\circ}$ 로 확인되어 골반 기울기 역시 통계학적으로 유의한 차이가 확인되었다 $(\mathrm{t}=-9.55$, $\mathrm{p}=0.003)$ (Table 3).

\section{IV. 고 찰}

본 연구는 스마트폰 어플리케이션을 이용하여 뇌졸중 환자의 등뼈 만곡과 골반 기울기를 측정하여 신뢰도를 알아보고, 뇌 졸중 환자와 건강한 성인의 등뼈 만곡과 골반 기울기를 비교 하여 뇌졸중 환자와 건강한 성인의 시상면상 정렬의 차이를 알아보기 위함이다.

연구의 결과를 살펴보면, 뇌졸중환자의 측정자내 신뢰도는 등뼈 뒤굽이각 0.93 , 골반 기울기 0.95로 확인되었다. Salamh과 Kolber(2014)의 연구에서는 2 명의 측정자가 30 명 의 건강한 성인을 대상으로 수평계(inclinometer)와 스마트폰 어플리케이션을 이용하여 선 자세에서 허리뼈 만곡을 측정하 고 신뢰도를 분석한 결과 수평계를 이용한 측정에서 측정자간 신뢰도와 측정자내 신뢰도는 각각 0.90과 0.85로 나타났으며, 스마트폰을 이용한 측정에서 측정자간 신뢰도와 측정자내 신 뢰도는 각각 0.96과 0.81로 나타났다. ${ }^{17)}$ Koumantakis 등 (2016)의 연구에서는 183명의 대학생을 대상으로 스마트폰 어플리케이션을 이용하여 선 자세에서 허리뼈 만곡과 골반 기 울기를 측정하고 신뢰도를 알아본 결과 허리뼈 만곡과 골반 기울기의 측정자내 신뢰도는 각각 $0.96,0.97$ 로 나타났으며

Table 2. The validity, standard error of measurement, and minimal detectable change

\begin{tabular}{cccc} 
& Validity & SEM $^{\mathrm{a}}$ & MDC $^{\mathrm{b}}$ \\
Thoracic kyphosis & 0.93 & 1.88 & 3.68 \\
Pelvic tilt & 0.93 & 1.10 & 2.17 \\
\hline
\end{tabular}

${ }^{a}$ SEM: standard error of measurement;

MDC:minimaldetectablechange

Table 3. Comparison of the thoracic kyphosis and pelvic tilt angle

\begin{tabular}{|c|c|c|c|c|}
\hline & $\begin{array}{c}\text { Stroke patients } \\
\text { (n=15) }\end{array}$ & $\begin{array}{l}\text { Healthy controls } \\
\qquad(n=15)\end{array}$ & $\mathrm{t}$ & $p$ \\
\hline Thoracic kyphosis $\left(^{\circ}\right)$ & $51.39 \pm 7.71$ & $32.49 \pm 2.29$ & -9.79 & $0.002^{*}$ \\
\hline Pelvic tilt $\left(^{\circ}\right)$ & $24.08 \pm 4.96$ & $11.15 \pm 1.68$ & -9.55 & $0.003^{*}$ \\
\hline
\end{tabular}


표준오차는 $2.13,1.61$ 로 나타났다. ${ }^{18)}$ 본 연구에서는 등뼈 만 곡과 골반 기울기를 측정하여 대상자와 측정부위는 선행연구 와 다르지만, 측정자내 신뢰도는 유사한 결과를 나타냈다. 최 소감지변화값은 등뼈 만곡이 3.68 , 골반 기울기가 2.17 로 확 인되었다. 이와 같은 결과는 뇌졸중 환자가 중재 이후에 등뼈 만곡이 $3.68^{\circ}$, 골반기울기가 $2.17^{\circ}$ 이상 향상된다면, 결과는 측정오차를 넘어선 임상적으로 의미 있는 결과로 해석할 수 있을 것이다.

뇌졸중 환자와 건강한 성인의 시상면상 등뼈 만곡을 비교 해본 결과 뇌졸중 환자군는 약 $51.4^{\circ}$ 건강한 성인은 $32.5^{\circ}$ 로 확인되어 뇌졸중 환자와 건강한 성인사이에는 약 $18.9^{\circ}$ 의 차 이가 확인되었다. Lewis와 Valentine(2010)의 연구에서는 건 강한 성인과 어깨 통증환자의 등뼈 만곡을 비교한 결과 건강 한 성인의 등뼈 만곡은 약 $35.5^{\circ}$ 였고, 어깨 통증환자는 약 $37.6^{\circ}$ 였다. ${ }^{15)}$ 뇌졸중 환자의 등뼈 만곡이 건강한 성인보다 큰 이유는 뇌졸중 환자의 척추 폄근 약화 때문일 것으로 생각된 다. Kasukawa 등(2010)은 노인의 등뼈 만곡은 척추 폄근의 근력과 밀접한 관계가 있다고 하였다. ${ }^{19)}$ 유사하게, Briggs 등 (2007)은 등뼈 만곡의 증가는 몸통을 바로 세우는 척추 폄근 의 근력과 척추 하중(spinal loads)과 밀접한 관련이 있다고 하였다. ${ }^{20)}$ 본 연구에서 뇌졸중 환자의 골반 기울기는 약 $24.1^{\circ}$, 건강한 성인의 골반 기울기는 약 $11.1^{\circ}$ 로 확인되어, 약 $13.0^{\circ}$ 의 차이를 보였다. Lopez-Minarro 등(2012)의 연구에서는 선 자세에서 건강한 성인의 골반 기울기를 측정한 결과 약 $11.3^{\circ}$ 로 확인되었다. ${ }^{21)}$ 유사하게 Roussouly 등(2005)의 연 구에서는 서 있는 동안 건강한 성인의 골반 기울기를 방사선 촬영으로 확인한 결과 약 $12.0^{\circ}$ 로 확인 되었다. ${ }^{22)}$ 이처럼 뇌 졸중 환자의 골반 기울기가 건강한 성인과 비교하여 골반 기 울기 값이 큰 이유는 뇌졸중 환자의 복부 근육 활성도가 건강 한 성인과 비교하여 낮아져 있고, 몸통의 폄근은 과도하게 활 성화 되어있기 때문으로 생각된다. ${ }^{23)}$

본 연구는 몇 가지 제한점이 있으며 추후 연구에서는 보완 되어야 할 것이다. 첫째, 뒤넙다리근 근육은 골반에 기시하기 때문에 뒤넙다리근의 길이와 골반 기울기와 상당한 연관이 있 다. ${ }^{21)}$ 하지만 본 연구에서는 뒤넙다리근의 길이를 고려하지 못했다. 추후 연구에서는 뒤넙다리근의 길이를 고려하여 골반 기울기를 측정해야 할 것이다. 둘째, 골반의 기울기는 몸통을 조절하는 능력과 상당한 관련이 있다. 본 연구에서는 선 자세 에서 뇌졸중 환자의 골반 기울기가 건강한 성인과 비교하여 전방으로 기울어져 있음을 관찰할 수 있었지만, 골반의 기울 기가 몸통조절능력에 미치는 영향에 대해서는 확인할 수 없었 다. 따라서 추후 연구에서는 골반 기울기가 몸통조절능력에 미치는 영향에 대한 연구가 이루어져 할 것이다.

\section{References}

1. Horak FB. Postural orientation and equilibrium: What do we need to know about neural control of balance to prevent falls? Age Ageing. 2006;35(2):7-11.

2. Pollock A, Baer G, Langhorne P, et al. Physiotherapy treatment approaches for the recovery of postural control and lower limb function following stroke: A systematic review. Clin Rehabil. 2007;21(5):395-410.

3. Ramirez-Moreno JM, Munoz-Vega P, Alberca SB, et al. Health-related quality of life and fatigue after transient ischemic attack and minor stroke. J Stroke Cerebrovasc Dis. 2019;28(2):276-84.

4. Porto AB, Okazaki VHA. Thoracic kyphosis and lumbar lordosis assessment by radiography and photogrammetry: A review of normative values and reliability. J Manipulative Physiol Ther. 2018;41(8):712-23.

5. Takahashi T, Ishida K, Hirose D, et al. Trunk deformity is associated with a reduction in outdoor activities of daily living and life satisfaction in community-dwelling older people. Osteoporos Int. 2005;16(3):273-9.

6. Di Bari M, Chiarlone M, Matteuzzi D, et al. Thoracic kyphosis and ventilatory dysfunction in unselected older persons: An epidemiological study in dicomano, italy. J Am Geriatr Soc. 2004;52(6):909-15.

7. Aruin AS. The effect of asymmetry of posture on anticipatory postural adjustments. Neurosci Lett. 2006;401(1-2):150-3.

8. Paillex R, So A. Changes in the standing posture of stroke patients during rehabilitation. Gait Posture. 2005;21(4): 403-09.

9. Vialle R, Levassor N, Rillardon L, et al. Radiographic analysis of the sagittal alignment and balance of the spine in asymptomatic subjects. J Bone Joint Surg Am. 2005;87(2):260-7

10. Fortin C, Feldman DE, Cheriet F, et al. Clinical methods for quantifying body segment posture: A literature review. Disabil Rehabil. 2011;33(5):367-83.

11. Doody MM, Lonstein JE, Stovall M, et al. Breast cancer mortality after diagnostic radiography: Findings from the u.S. Scoliosis cohort study. Spine (Phila Pa 1976). 2000;25(16):2052-63.

12. Ng JK, Kippers V, Richardson CA, et al. Range of motion and lordosis of the lumbar spine: Reliability of measurement and normative values. Spine (Phila Pa 
1976). 2001;26(1):53-60.

13. Palastanga N, Field D, Soames R. Anatomy and human movement: Structure and function. Elsevier Health Sciences. 2006.

14. McEvoy MP, Wilkie K, Williams MT. Anterior pelvic tilt in elite cyclists - a comparative matched pairs study. Physical Therapy in Sport. 2007;8(1):22-9.

15. Lewis JS, Valentine RE. Clinical measurement of the thoracic kyphosis. A study of the intra-rater reliability in subjects with and without shoulder pain. BMC Musculoskelet Disord. 2010;11:39.

16. Portney LG. Foundations of clinical research: Applications to practice 3th (third) edition. 2009.

17. Salamh PA, Kolber M. The reliability, minimal detectable change and concurrent validity of a gravity-based bubble inclinometer and iphone application for measuring standing lumbar lordosis. Physiother Theory Pract. 2014;30(1):62-7.

18. Koumantakis GA, Nikoloudaki M, Thacheth S, et al. Reliability and validity measurement of sagittal lumbosacral quiet standing posture with a smartphone application in a mixed population of 183 college students and personnel. Adv Orthop. 2016.

19. Kasukawa Y, Miyakoshi N, Hongo M, et al. Relationships between falls, spinal curvature, spinal mobility and back extensor strength in elderly people. J Bone Miner Metab. 2010;28(1):82-7.

20. Briggs AM, van Dieen JH, Wrigley TV, et al. Thoracic kyphosis affects spinal loads and trunk muscle force. Phys Ther. 2007;87(5):595-607.

21. Lopez-Minarro PA, Muyor JM, Belmonte F, et al. Acute effects of hamstring stretching on sagittal spinal curvatures and pelvic tilt. J Hum Kinet. 2012;31:69-78.

22. Roussouly P, Gollogly S, Berthonnaud E, et al. Classification of the normal variation in the sagittal alignment of the human lumbar spine and pelvis in the standing position. Spine (Phila Pa 1976). 2005;30(3): 346-53.

23. Verheyden G, Ruesen C, Gorissen M, et al. Postural alignment is altered in people with chronic stroke and related to motor and functional performance. J Neurol Phys Ther. 2014;38(4):239-45. 
